\title{
A gestão por meio da avaliação individualizante e competitiva como elemento comum nas políticas públicas e gerenciais contemporâneas: uma contribuição crítica a partir de Michel Foucault
}

The management by means of the individualizing and competitive assessment as a joint element in contemporary public and management policies: a critical contribution from the work of Michel Foucault

Tadeu de Paula Souza', Gustavo Tenório Cunha²

'Doutor em Saúde Coletiva pela Universidade Estadual de Campinas (UNICAMP) - Campinas (SP), Brasil. tadeudepaula@gmail.com

${ }^{2}$ Doutor em Saúde Coletiva pela Universidade Estadual de Campinas (UNICAMP) - Campinas (SP), Brasil. Professor da Universidade Estadual de Campinas (UNICAMP) - Campinas (SP), Brasil.

gustavotc9000@gmail.com
RESUMO: Neste artigo, realizam-se algumas reflexões sobre os desafios impostos à gestão das políticas públicas frente à hegemonia da lógica gerencial trazida pela racionalidade econômica neoliberal. Analisam-se, em especial, aspectos sobre a função estratégica que a avaliação vem assumindo na gestão de políticas públicas. As modulações nos processos de trabalho geradas pela lógica capitalista contemporânea implicaram novas estratégias de controle da produção, do trabalho e da vida. A partir da discussão sobre a 'a arte de governar neoliberal' proposta por Foucault (2008, 2009), espera-se ampliar o debate acerca dessa problemática por meio de exemplos concretos no campo da saúde e em outros campos, como a educação e a produção científica.

PALAVRAS-CHAVES: Neoliberalismo; governo; políticas públicas; avaliação.

\begin{abstract}
This article contains some reflections about the challenges posed to public policies' management vis-à-vis the hegemony of the managerial logic raised by the neoliberal economic rationality. It examines, in particular, aspects of the strategic role that evaluation is taking on in public policies' management. The framing in the work processes generated by the contemporary capitalist logic requires new strategies to control production, work and life. From the discussion on 'the neoliberal art of governing' proposed by Foucault $(2008,2009)$, we expect to broaden the debate about this issue through concrete examples in the field of health and in other fields, such as education and scientific production.
\end{abstract}

KEYWORDS: Neoliberalism; government; public policy; evaluation. 


\section{Introdução}

Estudiosos da avaliação têm apontado a correlação entre o surgimento das tecnologias de avaliação de programas sociais e a 'necessidade' de corte nos gastos públicos. A avaliação ganha especial relevância a partir dos anos 80 , momento em que a demanda crescente de racionalização de despesas se atrela ao imperativo de uma economia que se globaliza. A orientação por um Estado mínimo dirige as políticas dos governos no sentido da privatização e redução do investimento na saúde pública. Tal redução impôe uma direção de busca de eficiência em que o menor custo e a maior produtividade passam a ser importantes balizadores, num movimento de intensificação da avaliação como instrumento de uma gestão dirigida pelo avanço da racionalidade neoliberal. (VIACAVA et al., 2004).

Segundo Foucault (2008), o neoliberalismo surge como modelo de governo na Alemanha pós-nazismo, numa radicalização do liberalismo que pretende recuperar o Estado alemão a partir de uma nova relação Estado-mercado. $\mathrm{Na}$ impossibilidade de recuperar a governança da nação por meio da legitimidade da soberania estatal, as escolas do neoliberalismo encontram a situação perfeita para recuperar tal legitimidade a partir do fortalecimento do mercado.

Uma escola de teoria econômica que ganha destaque no pós-guerra é a escola de Friburgo, denominada ordo liberais. A estratégia discursiva dos ordo liberais identificou no nazismo um invariante antiliberal, afirmando que o nazismo foi o efeito máximo de uma direção política que investe na intervenção estatal da economia. A experiência do nazismo foi tomada como um exemplo limite e extremo para o qual convergiriam todas as economias que se pautassem por medidas ditas 'intervencionistas'. Assim, os ordo liberais iniciaram um movimento anti-intervencionista que permitia conectar políticas de cunho estatal de proteção social - como as propostas por Keynes e pelo New Deal americano - ao autoritarismo - como no nazismo. Para os ordo liberais alemães, a oposição política não estava essencialmente entre socialistas e capitalistas, mas entre práticas de governo ditas 'intervencionistas' e 'não intervencionistas'.

Por outro lado, iniciaram uma reformulação do próprio liberalismo propondo uma nova relação
Estado-mercado. Enquanto, no liberalismo, a liberdade de mercado era regulada pelo Estado, no neoliberalismo é o mercado que deverá regular o Estado. Pede-se que o mercado não seja meramente o princípio de limitação do Estado, mas o princípio de regulação interna do Estado. Em lugar de um mercado sob a vigilância do Estado, prefere-se um Estado sob a vigilância do mercado. Entendem que o sentido de não intervenção proposta pelos liberais estava mal formulado. Para os neoliberais, a troca e a concorrência não são dados naturais, mas fenômenos produzidos por um intenso esforço. "A concorrência é, portanto, um objetivo histórico da arte de governar, não um dado natural a se respeitar." (FOUCAULT, 2008, p.164).

A desigualdade como meio de garantir a concorrência deve ser ativamente produzida por uma arte de governar. É possível identificar nessa nova formulação um número tão grande de intervençóes quanto em uma política planificadora, mas suas naturezas são bem distintas. Enquanto, no liberalismo, a ação governamental se definia pela distinção entre agenda e não agenda, i.e., no que se deveria ou náo mexer, no neoliberalismo a questão fundamental gira em torno do como intervir no estilo governamental. O mínimo de Estado refere-se ao investimento em políticas públicas e não no arsenal de dispositivos de intervenção na vida da população e nos mecanismos de desregulamentação do mercado. A manutenção de suposto mercado livre exige inúmeras e incessantes intervençóes estatais.

Constitui-se um campo de intervenção que não é diretamente o mercado, mas que interfere no bom funcionamento do mercado. Não se deve, portanto, agir sobre o desemprego diretamente, mas sim sobre a estabilidade dos preços como condição de retomada da economia. Também não se deve agir diretamente sobre o preço, mas sobre um conjunto de variáveis que interferem no preço, como demografia, formação técnica, regime jurídico, clima, qualidade do solo etc. Para essa corrente, não existem desempregados, pois, no limite, o desempregado é um trabalhador em trânsito de um emprego para outro. Náo se deve interferir diretamente nesse trânsito, pois ele vai se regularizar a partir do fortalecimento da economia. Trata-se de 
adensar uma moldura não mercadológica que garanta bons efeitos econômicos.

A intervenção governamental deve ser discreta no nível econômico e intensa no nível dos condicionantes que garantem um alto nível concorrencial (FOUCAULT, 2008). Parte-se do princípio que o mercado é o regulador econômico e social, cabendo construir uma moldura institucional que garanta seu bom funcionamento. Cria-se, assim, uma individualização das políticas sociais em lugar de uma socialização nas políticas sociais. No limite, só há uma política social mercadologicamente viável: o crescimento econômico. São esses condicionantes que constituem um amplo campo de intervenção estatal gerador de uma espécie de moldura governamental. Essa orientação geral conduziria a um estilo governamental que consistiria em um modo de conceber as políticas sociais.

Nesse sentido, cabe perguntar: o que haveria em comum entre: o modo de funcionamento de políticas econômicas neoliberais com Sistemas Educacionais baseados em avaliaçôes; os sistemas de gestão e avaliação da produção científica predominantes no mundo; os sistemas de acreditação hospitalar na saúde; e as definiçóes de critérios de adoecimento e risco cada vez mais rigorosos - pressão arterial, glicemia, comportamentos de risco? Existiriam aspectos comuns sustentando e produzindo parte que seja dos modos de funcionamento dessas políticas? Existiriam, pelo menos parcialmente, pontos de convergência entre a gestáo de políticas e o modo como as pessoas passam a conceber sua própria saúde ou sua própria formação num exercício de gestão de si? Qual a função que a avaliação vem assumindo nessa lógica governamental?

Buscar-se-á traçar um ponto de convergência para essas práticas a partir da funçâo central que a avaliação vem tomando para a gestão de políticas públicas e o modo como se inscreve no nível do sujeito: o modo como nos conduzimos e nos concebemos. A hipótese que se defende com esta contribuição teórica, em diálogo com outros autores, é a de que o neoliberalismo transcendeu muito as políticas econômicas, resultando em um suporte cultural e ideológico que transformou a avaliação, antes um momento potencialmente crítico, reflexivo e de ampliação de conhecimento, em que se podia indagar sobre as finalidades e consequências de uma atividade, em um método de gestão e controle privilegiado, polivalente, que produz quase o exato oposto do que deveria.

Essa mudança produziu o silenciamento da complexidade, das perguntas a respeito das finalidades da atividade, da pertinência dos critérios de avaliação escolhidos, do jogo de forças, interesses e atores envolvidos e, finalmente, das interrogações em relação aos determinantes coletivos que influenciam nos resultados 'individuais' de avaliação. Acrescente-se que, onde e quando houver políticas públicas, estas deverão instigar a mesma concorrência individualizante. Trata-se da efetivação de uma aposta defendida pelos ordo liberais pela pseudopolítica social de privatização ou, como muito bem definiriam mais adiante os anarcoliberais norte americanos, por uma política social individual.

\section{O MODELO EMPRESA}

O modelo de sociedade que se produz e se propaga a partir desse momento é o de uma trama social que tem como base o modelo de empresa. $\mathrm{O}$ radicalismo da escola de Chicago dos anarcoliberais em relação aos ordo liberais foi o de levar para campos não econômicos os princípios dessa arte governamental a partir na noção de 'capital humano'. A palavra empreendedorismo pode entấo soar como mantra em todos os âmbitos da sociedade, sejam espaços públicos ou privados. As famílias, os indivíduos, os bairros, as instituiçóes públicas, ainda que educacionais ou de saúde, devem ser geridas como uma empresa.

A influência da economia norte-americana sobre as demais economias do mundo permitiu que o sonho ordo liberal se difundisse através de mecanismos de desregulamentação do capital financeiro. Não se trata, portanto, da construção de uma sociedade das massas uniformizadas, mas, ao contrário, "de obter uma sociedade indexada não na mercadoria e na uniformidade do mercado, mas na multiplicidade e na diferenciação da empresa" (FOUCAULT, 2008, p.204). As regras definidas pelo mercado permitem que nossas ações sejam calculáveis em termos de investimento e risco, sendo as regras morais uma espécie de variável dessa equação.

Sobre esse ponto pode-se destacar, em sintonia com este texto, a crítica da filósofa Marilena Chauí, chamando a atenção recentemente para o conservadorismo 
inerente ao bordão 'pela ética na política'. Para ela, este bordão supóe que a ética da política pública deveria subordinar-se à ética privada. Na democracia, tratar-se-ia, ao contrário, do desafio de construir e defender a ética DA política, "que não depende das virtudes morais das pessoas privadas dos politicos e sim da qualidade das instituiçóes públicas enquanto instituiçóes republicanas" (CHAUÍ, 2013).

Nesse sentido, o neoliberalismo não define uma modalidade de governo em que a liberdade do indivíduo deve ser exaltada, mas gerida. O liberalismo é um consumidor de liberdades na medida em que delimita os modos de liberdade e os meios para geri-las. O arcabouço, ou moldura, se desdobra na hipervalorização de um saber técnico, supostamente neutro, mas indiscutível, que seria capaz de definir as sagradas regras de concorrência. Constrói-se, com imensa intensidade, uma relação de adoração quase cega pela luta pelo melhor lugar no ranking.

Assim, o Estado passa a ser limitado não só pelos direitos individuais como pela própria dinâmica do mercado como novo campo de produção de verdade. " $O$ homo economicus que se quer reconstruir não é o homem da troca, não é o homem consumidor, é o homem da empresa e da produção" (FOUCAULT, 2008, p.201). O homo economicus é sofisticado pela noção de 'capital humano'. As relações familiares são atravessadas por um modo de organização em que cálculos de risco devem ser aplicados sobre os sujeitos, que passam a ser entendidos como investimentos. No limite, o próprio sujeito econômico é uma empresa de si mesmo que deve ser investida, sendo ele próprio seu capital, seu produtor e sua fonte de renda.

O imperativo 'Você SA' se torna o modelo de sujeito para a economia de mercado neoliberal.

Por um lado, a execução virtuosa aparece como o máximo de atividade livre e criativa; por outro, temos uma prestação pessoal que indica os termos de uma nova escravidão. A clivagem entre estes dois polos não é sempre nitida (COCCO, 2009, p.91).
O sujeito do consumo não é uma realidade absoluta, pois o consumo é valorado na medida em que, ao consumir, produz. O próprio consumo é a produção da satisfação do homem-empresa.

\section{E deve considerar o consumo como uma ativi- dade empresarial pela qual o individuo, a par- tir de certo capital de que dispóe, vai produzir uma coisa que vai ser sua própria satisfação. (FOUCAULT, 2008, p.311).}

O sujeito neoliberal goza de uma liberdade suficiente e eficientemente administrada por si mesmo. Essa ilusão de individualidade é construída por uma imensa máquina de gestão que busca tanto estabelecer os parâmetros de eficiência como produzir uma subjetividade que valorize a disposição competitiva e pouco questionadora desses parâmetros e seus formuladores.

\section{‘AVALIACIONISMO’ ACRÍTICO E TRABALHO}

O que se denomina aqui 'avaliacionismo acrítico' tem sido o método escolhido para restringir gastos e concentrar o lucro, culpando 'a vítima' e legitimando reengenharias organizacionais e políticas focais. É um instrumento tanto de materialização como de produção de uma subjetividade capitalista baseada na culpabilização, segregação e infantilização, como aponta Guattari (1986). Essa nova ordem econômica torna-se mundialmente hegemônica, interferindo, inclusive, no modo de conceber políticas públicas de proteção social nos países que, a duras penas, tentam mantê-las.

No universo do trabalho, são vários os efeitos dessa arte de governar. A separação entre processos de planejamento e decisão e processos de execução do trabalho se aprofundou radicalmente nessa nova orientação governamental. Enquanto, no modelo da fábrica, o tempo do trabalho coincidia com o tempo de permanência na própria fábrica, no modelo empresarial o trabalho se torna cada vez menos localizável (NEGRI; HARDT, 2001). Num modelo de produção em que o trabalho não coincide temporalmente com a permanência num dado espaço físico, a avaliação ganha especial relevância para o controle da produçẫo e se torna tendência, 
principalmente, na área de prestação de serviços, como educação e saúde. A suposta liberdade com horários e modalidades de trabalho mais flexíveis é confrontada permanentemente pelas metas de produtividade. Nesse contexto, não é tão necessário um supervisor para verificar se o trabalho está sendo executado.

A concorrência e o controle sobre a definição dos parâmetros de avaliação podem garantir um grau de alienação e mais valia inimagináveis no início da revolução industrial (COCCO, 2011; NEGRI; HARDT, 2001). É desse modo que as definiçóes das políticas neoliberais, mesmo as públicas, se comunicam com a gestão das organizaçóes. $\mathrm{O}$ investimento ideológico na onipotência dos critérios de avaliação aumenta a capacidade de introjeção nos indivíduos desse ranking, dessas réguas, como fossem verdades incontestáveis e válidas universalmente. $\mathrm{O}$ debate a respeito dos problemas que ele produz e dos problemas que ele nâo resolve é evitado ao máximo. Paralelamente, gera-se uma proliferação de variações do trabalho do tipo consultoria em que o próprio trabalho passa a ser encarado como projeto, inserindo o indivíduo em uma situação de permanente avaliação.

Antecede ao neoliberalismo o transbordamento do modelo de produção para outras instituições, como escolas e hospitais. Vários autores apontaram esse fato tanto em relação ao modo de funcionamento como em relação às finalidades veladas de preparar pessoas para se adaptarem à organização fabril. $\mathrm{Na}$ educação, dentre muitos autores, destaca-se o sociólogo Rui Canario (2006), que, analogamente a Ivan Illich na década de 70 , pergunta até que ponto o preparo para a cidadania e vida política não diminuem à medida que o modelo escolar atual se torna dominante. $\mathrm{Na}$ saúde coletiva, Campos (2000) também aponta a presença do taylorismo na gestão das organizaçóes de saúde. A ênfase na disciplina, controle do tempo, disponibilizaçáo dos corpos no espaço compunha uma tecnologia geral das diversas instituiçốes num processo de docilização dos corpos para o aumento da produtividade (FOUCAULT, 1977). Como afirma Campos (2000), o taylorismo como formulado inicialmente não existe mais; suas propostas foram alteradas embora não eliminadas.

A partir do neoliberalismo, as mudanças no mundo do trabalho se traduzem por uma tendência à flexibilização que veio acompanhada de uma precarização dos contratos e perda de garantias trabalhistas. Não se está mais no modelo da fábrica, mas no modelo empresa ou nas ditas sociedades de controle (DELEUZE, 1992). A disciplina massificadora vai deixando de ter um valor de uso central, sendo ocupada por uma tecnologia que investe na competição individualizante. Nesse cenário, a avaliação vem se tornando ferramenta forte de controle da produção, uma vez que a disciplinarização dos corpos, embora não tenha desaparecido, já não ocupa lugar central na organização dos processos de trabalho. Embora isso não seja uma realidade absoluta nas instituiçóes de saúde, a crescente precarização vem sendo a moeda de troca das corporaçôes de diferentes categorias para uma maior flexibilização dos processos de trabalho.

De fato, o efeito colateral mais evidente dessa cultura avaliativa é que os trabalhadores, assim como os estudantes na escola, se distanciam das finalidades da instituição e se dedicam a obter os melhores resultados nas avaliaçôes. Howard Becker (1961), quando estudou uma escola médica estadunidense na década de 60 , já percebia que a grande preocupação dos estudantes não era a obtenção do conhecimento de que necessitariam em sua profissão, mas como conseguir 'dizer' o que a instituição desejava que dissessem. Certamente que os técnicos engajados na difusão da ideologia neoliberal se apressam em responder que, se os 'critérios forem bons...', os avaliados, mesmo - ou talvez principalmente - sem saberem o que estão fazendo, realizarão a missão institucional.

Essa é uma resposta habitual que, no entanto, minimiza e encobre 'efeitos colaterais' importantes, principalmente a produção de um trabalho alienado, senão ignorante, indiferente aos resultados e objetivos. E, como já dito, não é nova a pergunta a respeito do quanto o efeito alienante é realmente secundário ou, de fato, contribui significativamente para produzir melhores condiçóes de subordinação e manipulação das pessoas. Afinal, a história da humanidade é farta de tragédias, guerras e tiranias sustentadas na estupidez acrítica do trabalho - 'apenas cumpro ordens', 'só faço meu trabalho', dentre outros bordóes semelhantes. 


\section{O AVANÇO DO ‘AVALIACIONISMO’EM SAÚDE}

$\mathrm{Na}$ área de saúde, também se pode perceber a imensa influência do ideário neoliberal, reforçando práticas e paradigmas dominantes. Ao se apontar a influência das políticas neoliberais na saúde, está-se ressaltando um aspecto sinérgico a essas contribuiçóes da Filosofia e da Saúde Coletiva. Destacam-se planos correlatos: as tecnologias de gestão por avaliação nos serviços e no sistema de saúde, a cultura de normatização da percepção de saúde-doença por meio de parâmetros de normalidade diversos definidos por especialistas e a persistente focalização do debate sobre o processo saúde-doença, na esteira do uso simplista e acrítico de indicadores.

No plano gerencial, podem-se aplicar as consideraçóes gerais realizadas anteriormente com a observação de que o arranjo tripartite de gestão entre os entes federativos tem produzido alguma proteção contra sistemas mais absolutos de avaliação, principalmente se a política de saúde for comparada à política educacional. Existe risco de um 'avaliacionismo', principalmente quando se busca, na avaliação, critérios para distribuição de recursos em um contexto de escassez. E quando se espalha a cultura da acreditaçâo, incialmente restrita aos hospitais, torna-se perfeita a expressão do neoliberalismo na gestão de saúde.

Apesar disso, a avaliação é um tema importante e urgente no SUS, para o qual existe uma qualificada produção acadêmica, ainda pouco conhecida pela maior parte dos gestores. Por exemplo, Furtado (2001), analisando e questionando a gestão taylorista das organizaçóes de saúde, traça uma importante direção: as avaliaçóes poderiam servir como instrumento de apoio, de contribuição para aumentar a capacidade de análise e intervenção dos coletivos. Poderiam, dessa forma, ser um estímulo a que se discutam exatamente as finalidades da instituição, do trabalho. A articulação entre avaliação participativa e metodologia do apoio tem sido uma importante estratégia de realocar a função de avaliação nos processos de gestão.

Nesse caso, os atores envolvidos participariam da construção de indicadores e critérios para avaliar seu processo de trabalho. Tal processo não visa somente à construção em si de indicadores, mas a propiciar momentos de debate sobre objetos e objetivos da instituição a que pertence. Num contexto em que esse processo é apoiado por um agente externo, pode-se analisar o jogo de parcialidades entre os interesses próprios aos grupos e os interesses institucionais, possibilitando a construção de horizontes comuns aos diferentes interesses. A ênfase, nesse caso, encontra-se no fortalecimento da democracia institucional e capacidade crítica, sendo a avaliação um instrumento que pode e deve auxiliar tal processo.

A crítica ao 'avaliacionismo', dessa forma, também é uma crítica aos modelos de gestão em que a avaliação ganha destaque em relação à própria missão da gestão. A avaliaçâo sem apoio e com critérios definidos unilateralmente é um bom método de eliminação dos menos aptos segundo esses mesmos critérios, bem como de concentraçáo de recursos. Muitas vezes se produziu e produz o 'indicadorismo' - que leva à definição de prioridades não em função de necessidades singulares das comunidades mas da adequação à avaliação. É presente o risco da falácia de indução de ação por indicadores com alto grau de precisão e com baixo grau de validade para os diversos atores envolvidos numa determinada política (SANTOS FILHO; SOUZA; GONÇALVES, 2011).

$\mathrm{O}$ casamento de instrumentos de avaliação com distribuiçấo de recursos como principal mola propulsora e modo de indução de políticas costuma diminuir a potência construtiva das avaliaçóes, assim como a capacidade crítica. Ainda mais quando os recursos são escassos. Nesse modelo, a avaliação se torna o 'carro chefe' do processo de gestáo, atrelando repasses de recursos ao cumprimento de metas monitoradas sistematicamente.

Ao mesmo tempo, existe uma influência também na percepção dos indivíduos do processo saúde-doença que se expressa em uma cultura de medicalização (TESSER, 2010) da vida por meio de parâmetros de 'normalidade' - definidos por especialistas, de forma alguma, imunes aos interesses econômicos. Ivan Illich (1975) já apontava, na década de 70 , a relação entre as práticas e sistemas de saúde contemporâneos e a produção de iatrogenias, dentre estas a diminuição da capacidade das pessoas de lidar com a dor e com problemas de saúde outrora suportáveis. O que se pode destacar na relação com o neoliberalismo atual é a sinergia do homem-empresa-empreendedor e a 'individualização' da relação com parâmetros laboratoriais e comportamentais definidos por especialistas. Vive-se 
um reforço contínuo de uma falsa autoavaliação de saúde, em que prevalece uma permanente relação de busca de adequação à normalidade, de forma que o adoecimento é antecipado para uma condição de suscetibilidade, inerente à vida, e o sujeito é submetido ao aparato de controle da vida da biomedicina.

O homem-empresa é 'convidado' a governar a 'si próprio' a partir de parâmetros pré-definidos. Sentir-se adequado à 'norma' ganha um 'valor terapêutico', assim como realizar um procedimento diagnóstico:

O consumidor, devotado aos três ídolos - anestesia; supressão da angústia, e gerência de suas sensaçóes - rejeita a ideia de quem, na maioria dos casos, enfrentaria sua pena com muito maior proveito se ele próprio a controlasse." (ILLICH, 1975, p.140).

Afetos de medo e tristeza condicionados a uma métrica abstrata e cada vez mais rigorosa são potencializados, muitas vezes, sem sustentação nem mesmo dos parâmetros considerados científicos (GRIMES, 2002).

Paradigmático do processo de construção ideológica são os vários procedimentos de rastreamento, vulgarmente conhecidos como 'check-ups' (GØTZSCHE, 2012), sem fundamento científico que os sustente e até mesmo com evidências de que produzem danos em vários casos, tais como exames de mamografia precoces (BLEYER, 2012), tratamento da hipertensão arterial leve (DIAO, 2012), dentre outros. Embora o rastreamento de câncer de próstata, ainda defendido por muitos urologistas no Brasil, esteja incluído nesse grupo, o Instituto Nacional de Câncer defende que não há, até o momento, evidências científicas de que o rastreamento do câncer de próstata possa produzir mais benefício do que dano, recomendando que não se organizem açóes de rastreamento para o câncer da próstata e que homens que demandam espontaneamente a realização de exames de rastreamento, sejam informados por seus médicos sobre os riscos e benefícios associados a esta prática (INCA 2013).

Ou seja, tais 'check-ups' revelam que as pessoas e os profissionais se ocupam mais com as 'boas notas' e parâmetros duvidosos do que com a vida e os problemas reais, e menos ainda, com possíveis causas comuns dos problemas de saúde.

Todo esse processo dificulta também a compreensão dos problemas de saúde e suas soluçóes. Os determinantes sociais e suas causalidades políticas encontram dificuldade para ganhar a pauta do debate na área de saúde. A obesidade é exemplo ilustrativo de um problema complexo, fortemente determinado por um conjunto de políticas públicas ausentes ou equivocadas, frequentemente reduzido à sua dimensão individual e associado a um forte discurso moral. Emblemática também é a associação entre mortalidade infantil e pouca escolaridade materna. A escolaridade expressa um conjunto de determinantes sociais, inclusive a inadequação da escola tradicional, quando acessível, às especificidades de populações em situação de vulnerabilidade.

Frequentemente reproduz-se a lógica do 'avaliacionismo' acrítico e tudo se passa como se a mortalidade infantil fosse decorrente da ignorância materna. Naturalizam-se os determinantes sociais, as correlaçóes de força na sociedade e as políticas públicas ausentes ou equivocadas. $\mathrm{O}$ que se destaca é um contorno cultural em que o adoecimento pode ser mais facilmente envolvido por um julgamento moral individual. As forças coprodutoras das políticas públicas e seus diversos atores sociais seguem protegidas dos questionamentos públicos que poderiam transformá-las.

Em um modo neoliberal de governar, a avaliação se torna uma espécie de imperativo que vai desde a autoavaliação voltada para a própria saúde ao desempenho profissional, modelando uma subjetividade empresarial em meios propriamente não empresariais. Cria-se um contínuo entre a gestáo de si e a gestão de políticas em que a competitividade e o controle são sofisticados por sistemas de avaliação e definição de parâmetros supostamente ideais.

\section{O AVANÇO DO ‘AVALIACIONISMO' EM OUTROS MEIOS}

Podem-se tomar outras situaçóes concretas da vivência cotidiana nessas políticas para experimentar as hipóteses apresentadas. Um exemplo curioso é a própria cogestão das instituições científicas por meio de critérios de 
produtividade de publicação em determinadas revistas. Curiosamente, essas revistas, por meio das quais muitos países do mundo definem os critérios de qualidade das publicaçóes científicas em cada área de conhecimento, são, em grande parte, sediadas em poucos países, não escolhidos aleatoriamente, dos quais saem os pesquisadores que definem as pautas dessas revistas.

Mesmo no Brasil, apesar do debate que vem ocorrendo em varias áreas do conhecimento sobre esse assunto, aceita-se de forma um tanto quanto natural que haja critérios definidos por um grupo pequeno de pesquisadores, geralmente de instituiçóes melhor posicionadas nesses mesmos critérios. Assim, questiona-se pouco que sejam critérios únicos, apesar da heterogeneidade institucional e regional brasileira. Ou seja, ainda que as instituiçóes de pesquisa e ensino tenham idades diferentes, situações diferentes e, supostamente, compromissos sociais diferentes, os critérios de avaliação e o ponto de chegada esperado são padronizados e predominante quantitativos. A ideia de critérios iguais para todos soa como se fosse 'justa'.

No caso da Saúde Coletiva, apesar dos imensos avanços recentes nesse debate, pode-se também questionar, ainda que reconhecendo o esforço do Centro de Estudos Brasileiro de Estudos de Saúde (CEBES) e da Associação Brasileira de Saúde Coletiva (ABRASCO), o quanto esse modelo de gestão por avaliaçáo estimula a exacerbação das diferenças e a competição entre pesquisadores e instituiçóes em detrimento da busca por pontos comuns, produçôes conjuntas e ações políticas decorrentes desses pontos comuns.

Seguramente, é mais difícil compor e juntar instituições e pesquisadores de forma sinérgica para enfrentar os mesmos grandes e complexos problemas de saúde da população num contexto produtivista e competitivo. Ainda mais quando grande parte dos recursos para pesquisa se concentra em poucas instituiçóes e a exacerbação das diferenças, muitas vezes pequenas, pode significar o acesso a esses recursos. Ainda quando existam critérios comuns que possam ser úteis para diferenciar instituições e pesquisadores, o que fazer com esses resultados? Qual seria o melhor uso dessas diferenças? O neoliberalismo tem uma resposta clara: darwinismo social. Nesse sentido, o sistema de gestão da produção científica hegemônico no mundo não facilita o debate sobre as finalidades da produção científica - podendo até mesmo impedi-lo -, assim como não facilita $o$ enfrentamento da fragmentação do conhecimento, da compreensão e da ação social.

Outro exemplo correlato, absolutamente conectado ao primeiro, é o imenso sistema de ranking em que se converteu a educação. As pedagogias, as dificuldades de cada contexto educacional, os determinantes de uma educação empobrecedora da existência capitaneada pela escola atual, filha da revoluçáo industrial (CANARIO, 2008), são assuntos menos importantes do que as notas obtidas pelos alunos nos diversos sistemas de classificação individualizante. Trata-se apenas de melhorar as notas, o rendimento. $\mathrm{O}$ mais bem educado é aquele que melhor sabe adequar-se às normas $\mathrm{e}$ colocar-se no ranking.

\section{Conclusão}

Repensar a função da avaliação e ampliar a possibilidade de interferir na seleção e construção de critérios de avaliação parece ser missão urgente. Pelo menos, é necessário dar um passo importante para reequacionamento dos jogos de força que aumentam a competitividade e concentração de poder em determinados grupos. Movimentos importantes vêm ampliando a possibilidade de articular a avaliação por meio do avanço da participação desses movimentos no sentido de subordiná-la à direção ético-política da democracia nas instituições de saúde. Parece que no centro de toda essa discussão encontra-se o eco do desafio da democracia num contexto de adequação geral à ordem mundial neoliberal. 


\section{Referências}

BECKER, H.S. et al. Boys in White: student culture in medical school. Chicago: University of Chicago Press, 1961.

BLEYER, A.; WELCH, G.H. Effect of Three Decades of Screening Mammography on Breast-Cancer Incidence, The New England Journal of Medicine, v.367, n.21, p.1998-2005, 2012. Disponível em: <http://www.nejm.org/doi/full/10.1056/ NEJMoa1206809>. Acesso em: 10 set. 2013.

CAMPOS, G.W.S. Equipes de referência e apoio especializado matricial: um ensaio sobre a reorganização do trabalho em saúde. Ciência e Saúde Coletiva - Abrasco, v.4, n.2, p.393-403, 1999.

Método Para Análise e Co-Gestão de Coletivos. São Paulo: Hucitec, 2000

CANARIO, R. A escola tem futuro? Das promessas às Incertezas. Porto Alegre: Editora Artmed, 2006.

. A escola: das "promessas" às "incertezas". Educação Unisinos, v.12, n.2, p.73-81, mai./ago., 2008. Disponível em: <http:// www.portal.santos.sp.gov.br/seduc/e107_files/downloads/ transferencias/escola_das_promessas_as_incertezas.pdf $>$. Acesso em: 01 out. 2013.

CHAUÍ, M. O Inferno Urbano e a Política do favor, da tutela e cooptação. Viomundo 27 de junho de 2013. Disponível em: <http://www.viomundo.com.br/denuncias/marilena-chauio-inferno-urbano-e-a-politica-do-favor-clientela-tutela-ecooptacao.html>. Acesso em 2 out. 2013.

COCCO, G. MundoBraz: o devir-Brasil do mundo, e o devir-mundo do Brasil. Rio de Janeiro: Editora Record, 2009.

O Trabalho sem Obra, a Obra sem Autor: a construção do Comum. In: BELISARIO, A.; TARIN, B. (Orgs.). CopyFight: pirataria e cultura livre. Rio de Janeiro: Azougue Editorial, 2011.

DELEUZE, G. Post-scriptum sobre as sociedades de controle. In: Conversações. São Paulo: Editora 34, 1992.

DIAO, D. et al. Pharmacotherapy for mild hypertension. Cochrane Database System Review, v.15, n.8, aug., 2012. Disponível em: <http://www.ncbi.nlm.nih.gov/pubmed/22895954>. Acesso em: 2 out. 2013.

FOUCAULT, M. Vigiar e Punir. Petrópolis: Vozes, 1977
Nascimento da Biopolítica. São Paulo: Martins Fontes, 2008.

Segurança, Território e População. Martins Fontes. São Paulo, 2009.

FURTADO, J. P. Um método construtivista para a avaliação em saúde. Ciência e Saúde Coletiva, v.6, n.1, p.165-181, 2001.

GØTZSCHE, P.C. et al. General health checks in adults for reducing morbidity and mortality from disease: Cochrane systematic review and meta-analysis. BMJ, n.345, p. 1-13, 2012. Disponível em: <http://www.bmj.com/content/345/bmj.e7191>. Acesso em: 2 out. 2013.

GRIMES, D.A.; SCHULZ K.F. Uses and abuses of screening tests. The Lancet, v.359, March 9, 2002.

GUATTARI, F.; ROLNIK, S. Micropolítica; Cartografias do Desejo. Petrópolis: Vozes, 1986. p.40-41.

ILLICH, I. Nêmesis da medicina: a expropriação da saúde. 1. ed. São Paulo: Nova Fronteira, 1975.

INSTITUTO NACIONAL DO CÂNCER (INCA). Rastreamento para o Câncer da Próstata: Diretrizes. Disponível em: <http://www1. inca.gov.br/inca/Arquivos/publicacoes/diretriz_rastreamento_ prostata.pdf>. Acesso em: 30 set. 2013.

NEGRI, A.; HARDT, M. Império. Rio de Janeiro: Record, 2001.

SANTOS FILHO, S.; SOUZA, T.P.; GONÇALVES, L.L.M. Avaliação como dispositivo de humanização em saúde. In. ONOCKO CAMPOS, R.; FURTADO, J. (Org). Desafios da avaliação de programas e serviços de saúde. Campinas: UNICAMP, 2011.

TESSER, C.D. Medicalização social e atenção à saúde no SUS. São Paulo: Hucitec, 2010.

VIACAVA, F. et al. Uma metodologia de avaliação do desempenho do sistema de saúde brasileiro. Ciência e Saúde Coletiva, v.9, n.3, p.711-724, 2004.

Recebido para publicação em outubro de 2013

Versão final em dezembro de 2013

Conflito de interesse: não houve

suporte financeiro: inexistente 